\title{
Bone Metastases Management during Pregnancy
}

\author{
Özlem SÖNMEZ
}

Department of Medical Oncology, Acıbadem Mehmet Ali Aydınlar University, Istanbul-Turkey

\section{Introduction}

The treatment of bone metastases includes various complementary approaches, such as the use of bisphosphonates, painkillers, chemotherapy, radiotherapy, and surgery according to personal symptoms. Physiotherapy and occupational therapy should also be utilized to improve mobility and to ensure physical adaptation.[1]

The management of metastases during pregnancy should be handled meticulously since both the mother and her fetus may be severely affected by the treatments used. It is recommended that the oncology, radiation oncology, and gynecology team decide together for the optimal timing of the treatments. Due to its teratogenic effect on the fetus during pregnancy, radiotherapy is contraindicated in all trimesters and chemotherapy in the first trimester. Denosumab and bisphosphonates are among the preferred treatments in patients with bone metastasis.[2]

It remains unexplored whether bisphosphonates cross the human placenta, but most bisphosphonates have a relatively low molecular weight, and transplacental passage can be expected. Information on human pregnancies regarding bisphosphonate use is limited to few retrospective and animal studies conducted in small groups.[3]

Bone toxicity or modeling abnormality in the fetus attributable to maternal bisphosphonate use has so far not been demonstrated in humans. In a series of 51 cases using bisphosphonates before or during pregnancy, no measurable risk for the embryo or fetus was documented, and it was recommended to be careful in terms of hypocalcemia in babies for a few days after birth. However, it has been recommended that these drugs should be discontinued in pregnant women and those trying to conceive a child until clarity is there whether bisphosphonates cross the placenta or not. In a series of 24 pregnant women exposed to alendronate in early pregnancy, it was shown that the mean week of gestation at birth was lower, mean birth weight decreased, and the rate of miscarriage increased, although no congenital anomalies were encountered in babies. In addition, when intravenous pamidronate or zoledronic acid was used in two pregnant women with metastatic breast cancer, the first woman gave birth at $36^{\text {th }}$ week, and the baby had a low serum calcium level that became normal within five days after delivery, and in the second case pamidronate was given at $28^{\text {th }}$ week, cesarean delivery occurred one week later, and the serum calcium level of the baby showed a rapid decrease after birth.[4-7] No skeletal abnormalities were seen in babies in two cases due to bisphosphonate therapy. Besides, some published studies have concluded that the use of bisphosphonates in the treatment of women of reproductive age has no adverse effects on getting pregnant. However, animal studies have shown that bisphosphonates remain in mineralized bone for several years and therefore have negative effects on the fetus, especially the skeletal system; therefore, use of bisphosphonates is not recommended during pregnancy.

Denosumab, another agent used in the management of bone metastases, interrupts this cycle by binding to the receptor activator of nuclear factor-kappa-B ligand (RANKL) and preventing the formation and function of osteoclasts.[6,7] When starting denosumab treatment, it is necessary to make a decision, especially about pregnancy. Studies conducted on monkeys and mice suggested that high-dose denosumab might harm the fetus, considering its association with increased prenatal or postnatal death and congenital anomalies, and its use in pregnant women is contraindicated.[8]

\section{Dr. Özlem SÖNMEZ}

Acıbadem Mehmet Ali Aydınlar Üniversitesi,

Tıbbi Onkoloji Anabilim Dalı,

İstanbul-Turkey

E-mail:dr.ozlemus@gmail.com 
In radiotherapy, the risk of exposure of the fetus to radiation is related to the trimester of the pregnancy. The main effect in the preimplantation period (10-14 weeks of gestation) is embryo loss. The organogenesis period (2-8 weeks of gestation) is the most sensitive when the risk of malformation is the highest. Studies have reported that radiation exposure in the pregnancy period after eight weeks is less likely to cause abnormalities, but it causes problems in terms of neurological development. The increased risk for childhood cancers was reported in some later published reviews on these newborns.

The lower dose in which radiation-induced abnormalities pose a risk in early pregnancy is $5 \mathrm{cGy}$. Standard breast radiotherapy is approximately $5000 \mathrm{cGy}$, so it should not be used as a treatment option. Post-mastectomy chest wall irradiation, like breast irradiation, poses the same risk to fetus and should only be considered after birth.

\section{References}

1. Mercadante S. Malignant bone pain: pathophysiology and treatment. Pain 1997;69(1-2):1-18.
2. National Comprehensive Cancer Network. (2021). Breast cancer (version 1.2021). Retrieved from https:// www.nccn.org/professionals/physician_gls/pdf/ breast.pdf

3. Djokanovic N, Klieger-Grossmann C, Koren G. Does treatment with bisphosphonates endanger the human pregnancy? J Obstet Gynaecol Can 2008;30(12):1146-8.

4. Dunlop DJ, Soukop M, McEwan HP. Antenatal administration of aminopropylidene diphosphonate. Ann Rheum Dis 1990;49(11):955.

5. Illidge TM, Hussey M, Godden CW. Malignant hypercalcaemia in pregnancy and antenatal administration of intravenous pamidronate. Clin Oncol (R Coll Radiol) 1996;8(4):257-8.

6. Culbert EC, Schfirin BS. Malignant hypercalcemia in pregnancy: effect of pamidronate on uterine contractions. Obstet Gynecol 2006;108(3 Pt 2):789-91.

7. Andreadis C, Charalampidou M, Diamantopoulos N, Chouchos N, Mouratidou D. Combined chemotherapy and radiotherapy during conception and first two trimesters of gestation in a woman with metastatic breast cancer. Gynecol Oncol 2004;95(1):252-5.

8. Amgen Inc. (2020). Xgeva (denosumab): Highlights of prescribing information. https://www.accessdata.fda. gov/drugsatfda_docs/label/2020/125320s201 lbl.pdf 